\title{
Florística e avaliação qualitativa da espécie Mangifera indica L. Nas praças de Santarém, Pará
}

\begin{abstract}
A arborização urbana é descrita como um dos mais importantes componentes do ecossistema das cidades, assim, deveria ser uma preocupação permanente de todo e qualquer planejamento devido aos benefícios que são proporcionados em sua consequência. Objetivou-se com esse estudo realizar um levantamento quantitativo das espécies arbóreas presentes em 11 praças do município de Santarém e caracterizar qualitativamente as mangueiras (Mangifera indica L.) dessas praças. Foram inventariados 209 indivíduos, sendo que $43 \%$ do total das árvores inventariadas são mangueiras. A alta porcentagem de mangueiras evidencia que a arborização das praças analisadas não favorece a preservação da biodiversidade local, estando mais propícia ao ataque de organismos xilófagos. As praças apresentam diversidade de espécies, no entanto, muitos indivíduos de uma mesma espécie, o que não é desejável pois torna a população mais susceptível a um declínio populacional devido ao ataque de pragas e doenças. Para avaliação qualitativa foram realizadas análises visuais do aspecto físico da árvores, considerando: sinais de doenças, sinais de cupins, fissuras no tronco e ocos. Das 90 mangueiras analisadas, 8 apresentaram sinais de doenças, 23 apresentaram sinais de cupins, 5 apresentaram fissuras e 2 apresentaram oco. Diante do exposto, observa-se a necessidade de um melhor planejamento, principalmente com relação à diversidade das espécies utilizadas e a manutenção das mesmas.
\end{abstract}

Palavras-chave: Arborização de Praças; Estado Fitossanitário; Mangueira; Cupins.

\section{Floristic and qualitative evaluation of the species Mangifera indica $L$. In the places of Santarém, Pará}

\begin{abstract}
Urban afforestation is described as one of the most important components of the urban ecosystem and thus should be a permanent concern of any planning due to the benefits that are provided in its consequence. The objective of this study was to carry out a quantitative survey of the tree species present in 11 plazas in the municipality of Santarém and to characterize the mangueiras (Mangifera indica L.) in these squares. 209 individuals were inventoried, and $43 \%$ of the total inventoried trees are mangueiras. The high percentage of mangoes shows that the afforestation of the squares analyzed does not favor the preservation of the local biodiversity, being more propitious to the attack of xylophagous organisms. The squares present a diversity of species, however, many individuals of the same species, which is not desirable because it makes the population more susceptible to a population decline due to the attack of plagues and diseases. For qualitative evaluation, visual analyzes of the physical aspect of the trees were performed, considering: signs of diseases, signs of termites, cracks in the trunk and hollows. Of the 90 mangueiras analyzed, 8 presented signs of diseases, 23 had termite signs, 5 presented cracks and 2 presented hollows. In view of the above, there is a need for better planning, especially in relation to the diversity of the species used and their maintenance.
\end{abstract}

Keywords: Afforestation of Squares; Phytosanitary Status; Mangueira; Termites.

Topic: Planejamento, Gestão e Políticas Públicas Ambientais

Reviewed anonymously in the process of blind peer
Received: $10 / 02 / 2019$

Approved: 25/03/2019
Karina de Aguiar Souza (iD

Universidade Federal do Oeste do Pará, Brasil

http://lattes.cnpq.br/1918070092289741

http://orcid.org/0000-0002-5862-0638

karinaaguiar12@hotmail.com

Silmara Ribeiro Leal (iD)

Universidade Federal do Oeste do Pará, Brasil

http://lattes.cnpq.br/6595393238585964

http://orcid.org/0000-0003-4574-6693

mribeiroleal@gmail.com

Janilce Lucas dos Santos (iD)

Universidade Federal do Oeste do Pará, Brasi

http://lattes.cnpq.br/8036796926961822

http://orcid.org/0000-0001-6954-3976

janilce.lucas@gmail.com

\author{
Jandreson Neves de Sousa (it) \\ Universidade Federal do Oeste do Pará, Brasil \\ http://lattes.cnpq.br/1460069229982455 \\ http://orcid.org/0000-0003-4126-6916 \\ jandresson.n.s@gmail.com \\ Mayra Piloni Maestri (iD \\ Universidade Federal do Oeste do Pará, Brasil \\ http://lattes.cnpq.br/2687102042811310 \\ http://orcid.org/0000-0002-8936-952X \\ mayrapmaestri@hotmail.com \\ Sara Freitas de Sousa (id) \\ Universidade Federal do Oeste do Pará, Brasil \\ http://lattes.cnpq.br/0444579834038751 \\ http://orcid.org/0000-0002-1305-8514 \\ sara freitas stm@hotmail.com
}

\section{Referencing this:}

SOUZA, K. A.; LEAL, S. R.; SANTOS, J. L.; SOUSA, J. N.; MAESTRI, M. P.; SOUSA, S. F.. Florística e avaliação qualitativa da espécie Mangifera indica L. Nas praças de Santarém, Pará. Revista Ibero Americana de Ciências Ambientais, v.10, n.2, p.351-361, 2019. DOI:

http://doi.org/10.6008/CBPC2179-6858.2019.002.0029 


\section{INTRODUÇÃO}

A arborização urbana é descrita como um dos mais importantes componentes do ecossistema das cidades, assim, deveria ser uma preocupação permanente de todo e qualquer planejamento devido aos benefícios que são proporcionados em sua consequência (VERAS, 1986; MILANO, 1988). A vegetação é um elemento essencial em cidades localizadas na zona tropical devido à sombra proporcionada pela copa das árvores, reduzindo a luminosidade, e pelo fato de folhas e ramos serem capazes de refletir a radiação solar, desse modo, minimizando temperaturas extremas na região (FREITAS et al., 2015).

Além disso, os elementos arbóreos colaboram para a manutenção do ciclo da água através da infiltração da água da chuva e sua evapotranspiração pelas folhas; melhoram a qualidade do ar, através da fixação do dióxido de carbono (CO2); auxiliam na sustentação do solo, impedindo a erosão, devido a agregação de suas partículas pelas raízes; fornecem flores com cores e odores variados, dessa maneira produzindo um cenário de grande beleza cênica à população; fornecem frutos atrativos para a comunidade e fauna local; além de serem atribuídos como ponto de referência para orientação e identificação nas cidades; contudo, a vegetação urbana possibilita a proximidade e convivência do homem com a natureza no espaço urbano construído (PORTO et al., 2013).

Todavia, para que a arborização assegure todos seus benefícios, a mesma deve ser realizada através de um Plano de Arborização Urbana, com o intuito de evitar problemas como queda de árvores, quebra de calçadas e conflitos com elementos urbanísticos, podendo ocasionar acidentes (CARVALHO, 2016). O Plano de Arborização Urbana engloba um conjunto de políticas, normas e diretrizes técnicas a respeito da arborização municipal, o que irá possibilitar a tomada de decisões sobre quaisquer aspectos relacionados à vegetação urbana, de ocorrência natural ou implantada. Abrangendo desde o desenvolvimento de programas de cadastramento, implantação, manejo e monitoramento da arborização viária e de áreas públicas e privadas, até programas de educação ambiental, pesquisa, capacitação técnica, cooperação, revisão e aperfeiçoamento da legislação (ANDRADE et al., 2015).

No planejamento da arborização deve-se considerar as características do local e seu entorno, abrangendo nesta caracterização a direção e o sentido dos ventos predominantes, o percurso da insolação e a perspectiva de visualização, além do espaço físico existente e presença de elementos urbanísticos como placas de sinalização e fiação elétrica (PORTO et al., 2013). Dentre as decisões mais importantes em um plano de arborização urbana está a escolha das espécies utilizadas e sua resistência às doenças e pragas (cupins, brocas, formigas carpinteiras, lagartas, cochonilhas, pulgões, dentre outras) que debilitam ainda mais as árvores, deixando-as doentes e sem sustentação adequada, trazendo perigo de tombamento e consequências, muitas vezes, trágicas em áreas habitadas, sem mencionar os transtornos e prejuízos causados após a queda de uma árvore (LINDENMAIER et al., 2008).

Um dos meios de se conservar a arborização urbana será o conhecimento de possíveis doenças que afetam as árvores, possibilitando o desenvolvimento de métodos de controle adequados e a garantia do vigor das espécies por muito mais tempo. Visto que árvores doentes são indesejáveis na arborização e 
preocupam pela possibilidade de quebra de fuste, causando sérios danos à fiação elétrica, às residências, carros e transeuntes (WIELEWSKI et al., 1999).

Lima Neto (2011) ressalta que a arborização urbana, por ser um serviço público, necessita de avaliação e monitoramento contínuo para que desempenhe adequadamente suas funções no meio urbano e benefícios sejam proporcionados, dando especial atenção aos aspectos culturais e de memória da cidade, em consonância com as demandas ecológicas e ambientais como a preservação da diversidade biológica local, uma vez que são muitos os problemas relacionados ao cultivo de árvores no ambiente urbano, como: estresse causado por insuficiente arejamento e déficit hídrico devido a pavimentação, agentes poluentes, temperaturas extremas, danos mecânicos causados pela população e, principalmente, recorrentes podas incorretas realizadas na tentativa de adequar o vegetal ao espaço físico na qual está inserido e sua coexistência com os elementos urbanísticos (MARCHETTI, 1997; RAGAZZI, 1998; SANTOS et al., 2001).

A utilização de espécies frutíferas, como a mangueira (Mangifera indica L.), é de grande polêmica entre cientistas da área da silvicultura urbana pois, apesar dos ganhos socioeconômico dos frutos produzidos, eles podem causar acidentes, sujeira, mau cheiro quando em estado de putrefação e atrair pequenos animais que se alimentam dos seus frutos doces e suculentos (ROPPA et al., 2007; SILVA et al., 2007).

A mangueira (Mangifera indica L.) é uma árvore frutífera, de grande porte, originária das Ásia, pertencente à família Anacardiaceae, sendo reconhecidas duas variedades: uma da Índia e outra proveniente tanto das Filipinas como do sudoeste da Ásia (SILVA, 2000). Para Andrade (2003), por diversas singularidades de adaptação ao ecossistema da região, o cultivo da espécie se destacou e tornou-se a principal árvore a ocupar ruas, avenidas e praças da cidade, além de ter grande aceitação por parte da população paraense.

Por ser uma árvore frutífera de grande porte e possuir raízes tabulares muito vigorosas, pode comprometer a infraestrutura urbana. Seus frutos grandes, pesados e suculentos, quando maduros, podem provocar diversos acidentes e danos a população, servindo de alimento para animais vetores e dispersores de doenças (JORGE et al., 2017). Nesse contexto, esse estudo teve como objetivo realizar um levantamento quantitativo das espécies arbóreas presentes em 11 praças do município de Santarém, oeste do estado do Pará, e avaliar a frequência e o estado fitossanitário das mangueiras (Mangifera indica L.) presente nas áreas de estudo.

\section{METODOLOGIA}

Este estudo foi desenvolvido em 11 praças do município (Barão de Santarém, Bosque da cidade, Liberdade, Mascotinho, Matriz, Mirante, Nossa Senhora das Graças, Pescador, Rodrigues dos Santos, São Sebastião e Três Patetas); as praças selecionadas apresentam uma grande quantidade de visitadas e transeuntes devido suas localizações (Figura 1). 


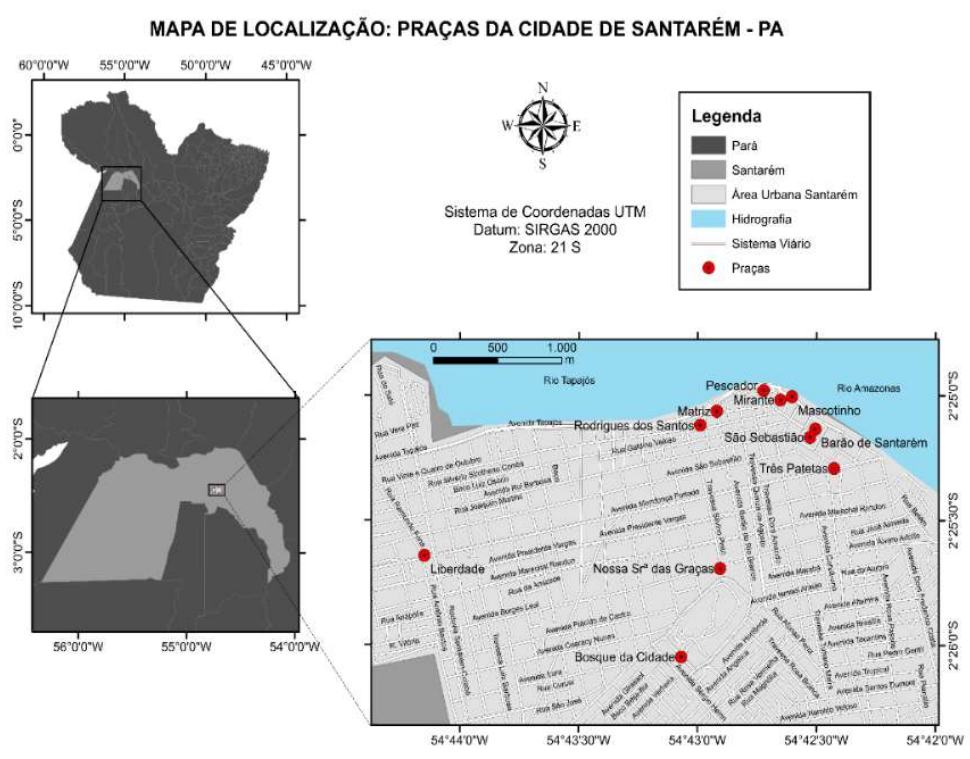

Figura 1: Mapa da localização das praças utilizadas no estudo, Santarém/PA.

O município tem como coordenadas geográficas municipais: $22^{\circ} 25^{\prime} 30^{\prime \prime}$ de latitude Sul e 54 $42^{\prime} 50^{\prime \prime}$ de longitude Oeste, O clima dominante na região, segundo a classificação de Koppen, é quente e úmido, característico das Florestas Tropicais, pois o mesmo não está sujeito às mudanças significativas de temperatura devidas sua proximidade da linha do equador (SILVA, 2016). A temperatura média anual varia de 25 a a 28 으, com umidade relativa média do ar de $86 \%$. A precipitação média anual gira em torno de 2.282,6 mm com maior intensidade no chamado período de 'inverno', que ocorre de dezembro a maio, e nos meses de junho a novembro, ocorre o período mais seco, correspondendo ao 'verão' regional (IBGE, 2015).

O inventário a $100 \%$ foi realizado com o auxílio de planilhas estruturadas pelo Projeto Floresta Urbana em parceria com a Universidade Federal do Oeste do Pará (UFOPA), Secretaria Municipal de Meio Ambiente de Santarém (SEMMA), Instituto de Desenvolvimento Florestal e da Biodiversidade do Estado do Pará (Ideflor-bio) e Secretaria Municipal de Agricultura e Pesca (SEMAP).

O levantamento vegetativo realizado para análise quantitativa foi feito através de identificação botânica das espécies arbóreas bem como das palmáceas, individualmente. A identificação das famílias e espécies vegetais arbóreas mais comuns e frequentes foram identificadas in loco e, as demais, através de bibliografia, comparação entre o material botânico coletado e o material de herbário, além de consulta a identificador botânico no Laboratório de Sementes Florestais da Universidade Federal do Oeste do Pará (UFOPA).

Quanto à origem fitogeográfica das espécies, consideraram-se nativas aquelas originárias de formações vegetais ocorrentes no Brasil e as espécies que ocorrem em outros ecossistemas diferentes dos que aparecem em território brasileiro foram consideradas exóticas. Para avaliação qualitativa foram realizadas análises visuais do aspecto físico da árvores, considerando: (a) sinais de doenças, considerando os aspectos gerais da árvore; (b) sinais de cupins, conforme Amaral (2002), verificando a existência ou não dos organismos xilófagos, bem como os danos provocados por eles; (c) fissuras no tronco e (d) presença de ocos. 
Os dados utilizados neste estudo foram tabulados em planilhas do software Microsoft Excel 2013 e, posteriormente, foram confeccionados gráficos e tabelas.

\section{RESULTADOS}

A partir do inventário foram contabilizados e analisados 209 indivíduos arbóreos, compostos por 28 espécies e distribuídos em 17 famílias (Tabela 1). Dentre as espécies contabilizadas, 16 delas são nativas e 11 são exóticas. Do total de árvores encontradas, 11 árvores não puderam ser identificadas em função de podas drásticas e pela ausência de folhas, flores ou frutos, totalizando aproximadamente 5,3\% da amostra. A mangueira foi a espécie mais frequente nas praças selecionadas, com 90 indivíduos, representando $43 \%$ da amostra (Figura 2).

Tabela 1: Lista das espécies arbóreas das praças inventariadas separadas por família, nome científico, nome popular, número de indivíduos e origem.

\begin{tabular}{|l|l|l|l|l|}
\hline Família & Nome Científico & Nome Popular & $N^{\circ}$ De Indivíduos & Origem \\
\hline Sapotaceae & Pouteria pachycarpa & Abiurana & 1 & Nativa \\
\hline Oleaceae & Olea europea & Azeitona & 1 & Exótica \\
\hline Arecaceae & Mauritia flexuosa & Buriti & 1 & Nativa \\
\hline Anacardiaceae & Anacardium occidentale & Cajueiro & 1 & Nativa \\
\hline Combretaceae & Terminalia catappa & Castanhola & 14 & Exótica \\
\hline Caesalpiniaceae & Copaifera sp. & Copaibarana & 3 & Nativa \\
\hline Arecaceae & Cocos nucifera & Coqueiro & 5 & Exótica \\
\hline Bignoniaceae & Crescentia amazônica & Cuieira & 1 & Nativa \\
\hline Moraceae & Ficus carica & Figo & 10 & Exótica \\
\hline Fabaceae & Delonix regia & Flamboyant & 1 & Exótica \\
\hline Bignoniaceae & Tabebuia serratifolia & Ipê Amarelo & 19 & Nativa \\
\hline Myrtaceae & Syzygium malaccense & Jambeiro & 6 & Exótica \\
\hline Rutaceae & citrus sp. & Limoeiro & 1 & Exótica \\
\hline Anacardiaceae & Mangifera indica L. & Mangueira & 90 & Exótica \\
\hline Simaroubaceae & Simarouba amara & Marupá & 1 & Nativa \\
\hline Malpighiaceae & Byrsonima sp. & Murici & 1 & Nativa \\
\hline Meliaceae & Azadirachta indica & Nim & 8 & Exótica \\
\hline Chrysobalanaceae & Licania tomentosa & Oiti & 5 & Nativa \\
\hline Chrysobalanaceae & Licania rígida & Oiticica & 3 & Nativa \\
\hline Fabaceae & Clitoria fairchildiana & Palheteira & 3 & Nativa \\
\hline Arecaceae & Euterpe oleraceae & Palmeira & 1 & Nativa \\
\hline Caesalpiniaceae & Cassia ferrugínea & Pingo De Ouro & 2 & Exótica \\
\hline Pinaceae & Pinus sp. & Pinus & 10 & Exótica \\
\hline Fabaceae & Andira parvifolia & Alvineira & 2 & Nativa \\
\hline Fabaceae & Pterodon emarginatus & Sucupira & 4 & Nativa \\
\hline Anacardiaceae & Spondias mombin & Taperebá & 1 & Nativa \\
\hline Fabaceae & Adenanthera pavonina & Tento Vermelho & 3 & Nativa \\
\hline N. I.* & & & 11 & \\
\hline
\end{tabular}

${ }^{*}$ N. I. = Não Identificados

As praças Barão, Três Patetas, Mirante e São Sebastião não apresentam Mangueiras (Mangifera indica L.) com sinais de doenças, em contrapartida, a praça Rodrigues dos Santos (37,5\%), seguida das praças Matriz (33,3\%), Pescador (28,6\%) e Mascotinho (28,6\%) apresentaram árvores da mesma espécie com sinais de doenças (Figura 3). Na figura 3 constam apenas as praças nas quais foram encontradas árvores com os sinais acima mencionados. 


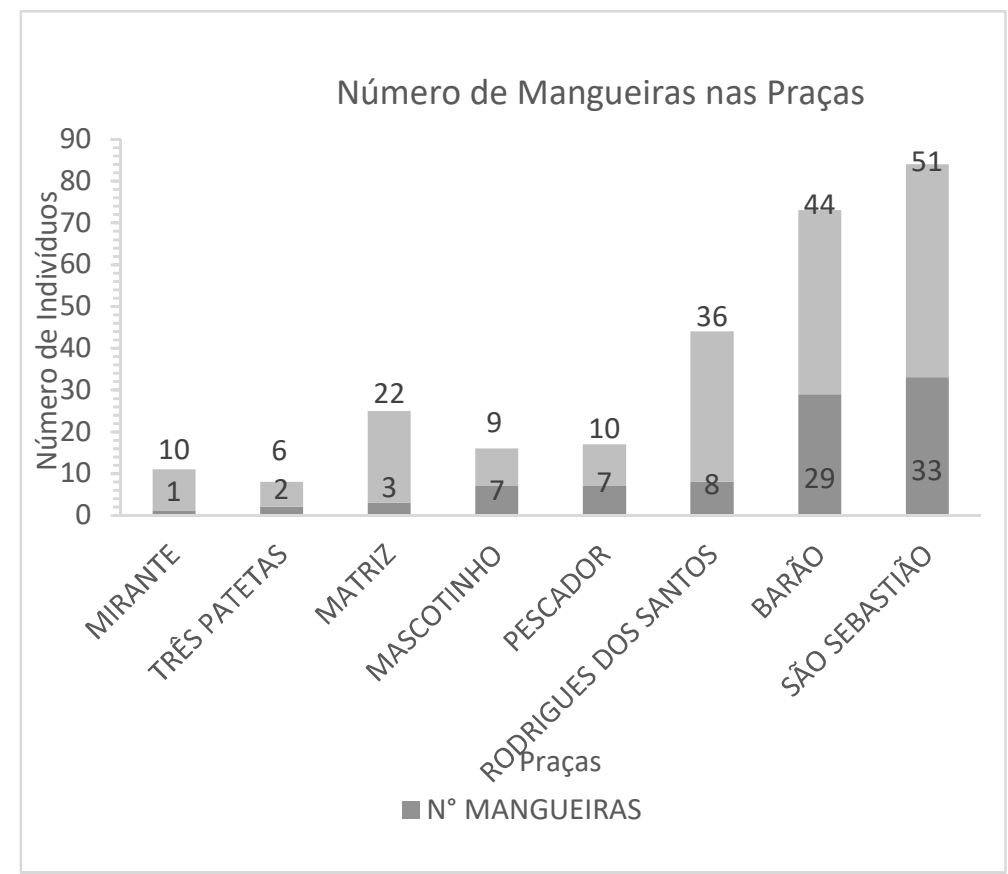

Figura 2: Levantamento das Mangueiras (Mangifera indica L.) nas praças da cidade de Santarém/PA.

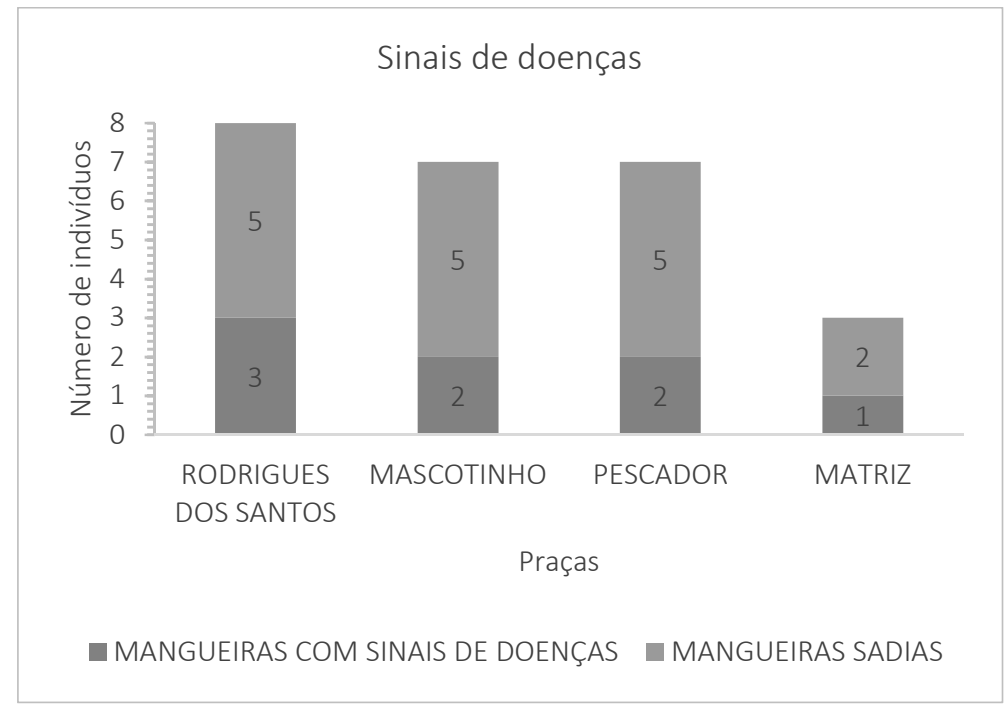

Figura 3: Sinais de doenças nas Mangueiras (Mangifera indica L.) das praças de Santarém/PA.

Em relação a presença de térmitas, as praças Mirante e São Sebastião não apresentaram mangueiras (Mangifera indica L.) com a presença de cupins. As praças do Pescador e Três Patetas apresentaram 100\% das mangueiras com sinais de ataque de térmitas. As praças Rodrigues dos Santos, Matriz, Barão e Mascotinho apresentaram mangueiras (Mangifera indica L.) com presença de cupins, com 71,4\%, 66,7\%, $17,2 \%$ e $14,3 \%$ respectivamente (figura 4 ).

A Figura 5 ilustra a ocorrência de cupins em uma mangueira na praça Mascotinho. Todos os indivíduos apresentaram fissuras naturais na casca. Apenas as praças Barão $(13,8$ \%) e Matriz $(33,3 \%)$ apresentaram árvores com fissuras relacionadas a organismos xilófagos. Apenas na praça Barão $(6,9 \%)$ foram constatados indivíduos com oco. 


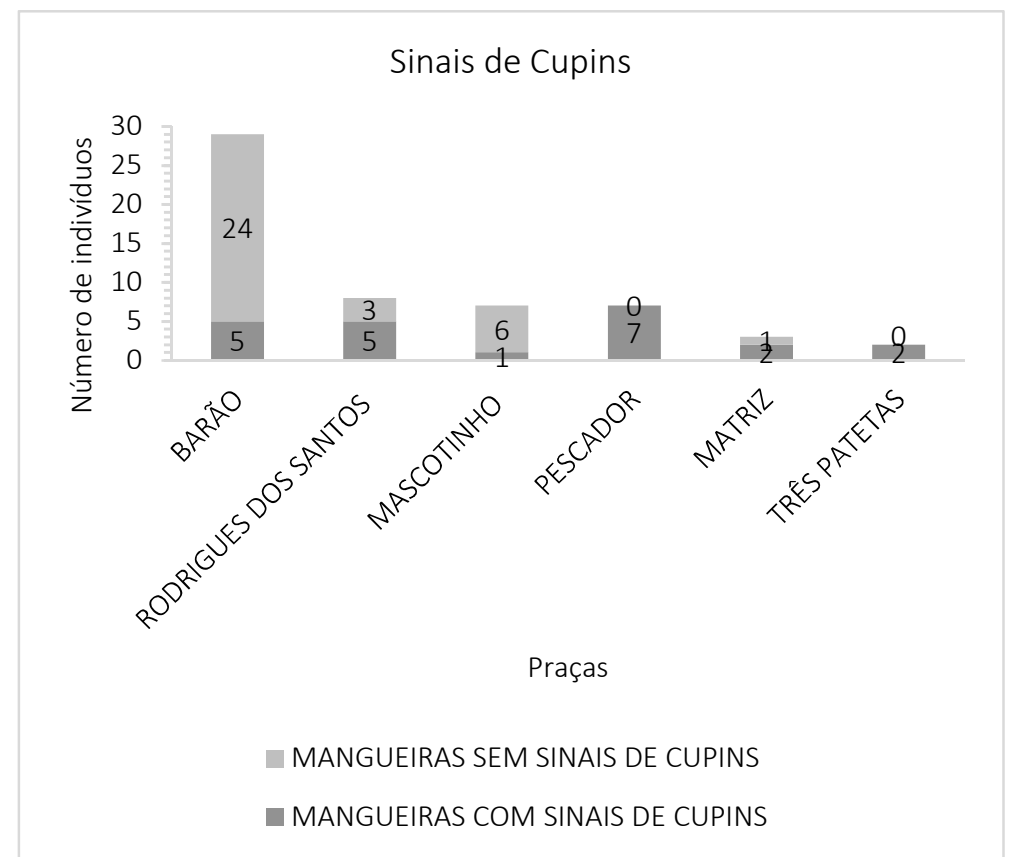

Figura 4: Levantamento das Mangueiras (Mangifera indica L.) com cupins das praças de Santarém/PA.

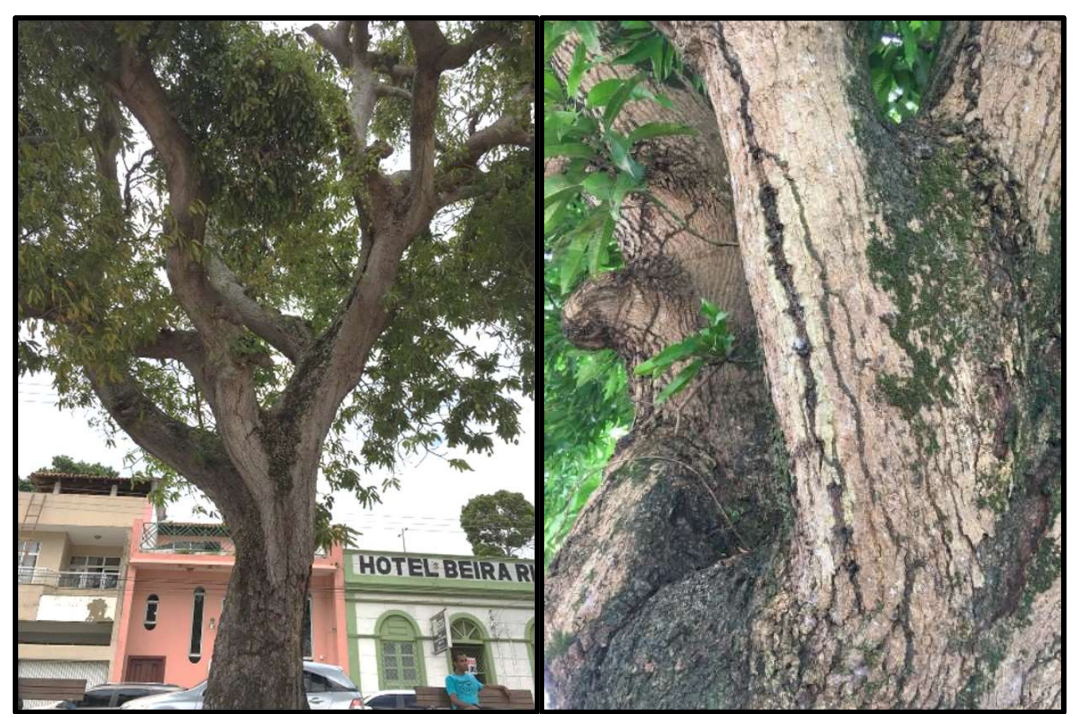

Figura 5: Incidência de térmitas na mangueira (Mangifera indica L.).

\section{DISCUSSÃO}

O uso de espécies nativas na arborização urbana é de extrema importância devido apresentarem maior resistência a pragas e doenças, além de permitirem a criação de um banco genético in-situ e oferecerem muitos benefícios para a fauna nativa, como fonte de abrigo e alimento (BIONDI et al., 2008; BRUN et al., 2007).

O resultado obtido nesse estudo demonstra um maior número de espécies nativas compondo a arborização das praças levantadas. É frequente encontrar em bibliografias um percentual maior de espécies exóticas em levantamentos da arborização de praças (GOMES et al., 2016; KRAMER et al., 2012; SANTOS et al., 2011; MOSER et al., 2017), porém, no estudo de Santos et al. (2017), ao diagnosticarem a arborização de um parque urbano, inaugurado no ano de 2005, as espécies nativas também sobressaíram, correspondendo a 73,91\% do total de indivíduos amostrados, indicando um cuidadoso planejamento da arborização avaliada. 
Conforme Redin et al. (2010), esse fato pode ocasionar riscos relacionados à longevidade por meio de declínio populacional e ataque de pragas e doenças. Das 90 mangueiras analisadas, 8 apresentaram sinais de doenças, 23 apresentaram sinais de cupins, 5 apresentaram fissuras e 2 apresentaram oco. Apesar de serem identificadas várias espécies, os maiores números de indivíduos encontrados concentram-se nas mesmas espécies. Redin et al. (2010) e Miller et al. (2015) recomendam que a frequência de uma única espécie não ultrapasse 15\%, devido razões estéticas e fitossanitárias. Sendo importante mencionar que o domínio de poucas espécies na arborização de um município oferece sérias implicações para a biodiversidade do ecossistema urbano, sendo de suma importância para a ampliação e fixação da fauna, manutenção do equilíbrio biológico e controle de pragas, além de ganhos na cartela de cores paisagística (MILANO, 1988; LINDEMAIER et al., 2008).

A mangueira representou $43 \%$ da amostra, situação semelhante ao relatado no trabalho de Bessa et al. (2013) sobre o diagnóstico qualitativo e quantitativo de arborização da praça batista campos em Belém do Pará, onde a mangueira foi a espécie mais frequente na praça estudada; o autor ressaltou que a espécie é inadequada para a arborização do espaço, podendo causar acidentes às pessoas que ali circulam devido ao tamanho de seus frutos.

Milano (2000) retrata que deve haver um equilíbrio na diversidade das espécies, no entanto, em seu estudo, as mangueiras também estão acima da média recomendada. O mesmo autor acentua ainda que a baixa heterogeneidade de espécies é recorrente nas áreas urbanas plantadas, no entanto, isso não é uma situação desejável e indica um mau planejamento da arborização urbana.

O ambiente urbano não é adequado ao ciclo de vida das árvores plantadas devidos aos inconvenientes que têm sua origem na ação de agentes bióticos como doenças em raízes, doenças do tronco, doenças foliares e plantas parasitas; e abióticos, como temperatura, umidade, luminosidade e distúrbios climáticos. A ação antrópica pode causar danos diretos através de ferimentos, ou indiretos, através da poluição e manejo inadequados. Como resultados, poderão ocorrer desde pequenas lesões, que irão expor os indivíduos ao patógeno, até a morte dos indivíduos mais afetados (AUER, 1996).

Dentre as doenças mais comuns que ocorrem nas mangueiras estão: a antracnose (Colletotrichum gloeosporioides), a morte descendente ou seca-de-ponteiros (Asiodiplodia theobromae), a malformação vegetativa e floral (Fusarium subglutinans), o oídio (Oidium mangiferae) e a seca-da-mangueira (Ceratocystis fimbriata), além destas doenças causadas por fungos, pode ocorrer a mancha angular, causada pela bactéria Xanthomonas campestris pv. Mangiferae indicae (BATISTA et al., 2008).

Em relação aos cupins, Brazolin (2009) cita inúmeros casos de ataques em árvores urbanas, destacando sobre a ocorrência de cupins nas raízes, os quais avançaram seu ataque para o cerne das árvores, com a infestação iniciando-se no interior do seu tronco e nem sempre precedida ou associada a um ferimento. Apesar da maioria dos cupins preferirem atacar os tecidos já deteriorados por fungos, diversos autores relatam que há espécies que atacam, também, a madeira sã.

Duarte et al. (2008) afirma que os cupins não possuem preferência por determinadas espécies arbóreas, o ataque está relacionado às espécies de árvores presentes no local e a distância a que elas se 
encontram umas das outras. Os térmitas penetram pelas raízes das árvores e atacando basicamente o seu cerne, tornando-as ocas em estágio avançado de colonização, com a construção de túneis e a presença de rachaduras na casca, presença de feridas e reentrâncias (AMARAL, 2002).

Uma das causas de fissuras na árvore é o crescimento secundário, devido a circunferência da parte externa ser menor do que a interna que está sendo formada, fazendo com que as fendas se abram, muitas vezes chegando ao floema. É nesse momento que há a entrada de organismos xilófagos, seja fungos, bactérias ou insetos. Esses organismos podem também abrir seu próprio caminho, no entanto, as defesas das plantas muitas vezes estão na casca externa (feloderme), então ao entrarem na fissura, eles burlam as barreiras químicas e físicas da planta, chegam ao floema e ao alburno, onde a deposição de extrativos praticamente ainda não ocorre, encontrando, dessa forma, abundante fonte de alimentos (RAVEN et al., 2014).

Barcelos (2000) afirma que o oco favorece a degradação dos tecidos pela presença de microorganismos e representa um importante micro-habitat para insetos e outros macroinvertebrados, propiciando condições favoráveis ao desenvolvimento de organismos xilófagos. Uma hipótese para explicar a existência de árvores vivas ocadas em áreas tropicais é de que os ocos ocorreriam em virtude do solo pobre em nutrientes, fazendo com que o apodrecimento na parte central (cerne) de árvores vivas permitisse uma adaptação para obtenção de nutrientes, especialmente nitrogênio, em locais pobres desse nutriente (APOLINÁRIO et al., 2004).

\section{CONCLUSÕES}

Considerando que a arborização das praças avaliadas cumpra suas funções ambientais, ofertando melhoria na qualidade de vida para os habitantes, podemos destacar que é necessário um melhor planejamento e gestão destas, principalmente em relação à diversidade das espécies utilizadas e na manutenção das mesmas.

A alta porcentagem de mangueiras evidencia que a arborização das praças analisadas não favorece a preservação da biodiversidade local, estando mais propícia ao ataque de organismos xilófagos. Os locais de estudo considerados pontos históricos da cidade, e, consequentemente, apresentam uma arborização antiga, o que reflete na sanidade das árvores, dessa forma, necessitando de maiores cuidados. Portando, recomenda-se que sejam realizados constantes programas de monitoramento, manejo e, quando necessário, substituição da vegetação presente nas praças do município, propiciando melhores serviços ambientais, ecossistêmicos, sociais e econômicos.

\section{REFERÊNCIAS}

AMARAL, R. D. A. M.. Diagnóstico da ocorrência de cupins xilófagos em árvores urbanas do bairro de Higienópolis na cidade de São Paulo. Dissertação (Mestrado em Recursos Florestais) - Universidade de São Paulo, Piracicaba, 2002.

ANDRADE, M. N. M. M.; JERÔNIMO, C. E. M.. Diagnóstico da arborização do espaço urbano da cidade de João Pessoa, PB.
Revista Eletrônica em Gestão, Educação e Tecnologia Ambiental. Santa Maria, v.19, n.3, p.194-208, 2015. DOI: http://doi.org/105902/2236130817785

APOLINÁRIO, F. E.; MARTIUS, C.. Ecological role of termites (Insecta, Isoptera) in tree trunks in central Amazonian rain 
forests. Forest Ecology and Management, v.194, p.23-28, 2004. DOI: https://doi.org/10.1016/i.foreco.2004.01.052

AUER, C. G.. Doenças de árvores urbanas. Colombo: EMBRAPA-CNPF, 1996

BARCELOS, P. R. A.. A dendrocirurgia. In: CURSO SOBRE MANEJO DA ARBORIZAÇÃO URBANA E DENDROCIRURGIA. Anais. Jaboticabal: Funep, 2000.

BATISTA, D. C.; BARBOSA, M. A. G.. Doenças da mangueira. In: SIMPÓSIO INTERNACIONAL DE VITIVINICULTURA, FEIRA NACIONAL DA AGRICULTURA IRRIGADA, 1. Anais. Petrolina: Embrapa Semi-Árido, 2008.

BESSA, M. S. C.; RODRIGUES, R. P.; SANTOS, C. R. C.. Diagnóstico Qualitativo e Quantitativo de Arborização da Praça Batista Campos em Belém-PA. In: CONGRESSO BRASILEIRO DE GESTÃO AMBIENTAL SALVADOR/BA, 4. Anais. 2013.

BIONDI, D.; LEAL, L.. Caracterização das Plantas Produzidas no Horto Municipal da Barreirinha - Curitiba / PR. Revista da Sociedade Brasileira de Arborização Urbana, Piracicaba, v.3, n.2, p.20-36, 2008.

BRANZOLIN, S.. Biodeterioração, anatomia do lenho e análise de risco de queda de árvores de tipuana, Tipuana tipu (Benth.) O. Kuntze, nos passeios públicos da cidade de São Paulo, SP. Tese (Doutorado em Recursos Florestais) Universidade Federal de São Paulo, São Paulo, 2009.

BRUN, F. G. K.; LINK, D.; BRUN, E. J.. O Emprego da Arborização na Manutenção da Biodiversidade de Fauna em Áreas Urbanas. Revista da Sociedade Brasileira de Arborização Urbana, Piracicaba, v.2, n.1, p.117-127, 2007. DOI: http://dx.doi.org/10.5380/revsbau.v2i1.66253

CARVALHO, L. A.; NOGUEIRA, J. F.; LEMOS, J. R.. Inventário da arborização de um bairro da cidade de Parnaíba-Piauí, com utilização de informação geográfica. Revista Casa da Geografia de Sobral, Sobral, v.18, n.1, p.100-117, 2016.

DUARTE, F. G.; SANTOS, G. A.; ROSADO, F. R.; DELARIVA, R. L.; SAMPAIO, A. C. F.. Cupins (Insecta: Isoptera) na arborização urbana da zona 1 de Maringá-PR. Revista em Agronegócios e Meio Ambiente, v.1, n.1, p.87-99, 2008.

FREITAS, W. K.; PINHEIRO, M. A. S.; ABRAHÃO, L. L. F.. Análise da arborização de quatro praças no bairro da Tijuca, RJ, Brasil. Floresta e Ambiente, Rio de Janeiro, v.22, n.1, p.23-31, 2015.

DOI: http://dx.doi.org/10.1590/2179-8087.025612

GOMES, E. M. C.; RODRIGUES, D. M. S.; SANTOS, J. T.; BARBOSA, E. J.. Análise quali-quantitativa da arborização de uma praça urbana do Norte do Brasil. Nativa, Sinop, v.4, n.3, p.179-186, 2016. DOI: http://doi.org/10.14583/2318$\underline{7670 . v 04 n 03 a 12}$

IBGE. Instituto Brasileiro de Geografia Estatística. Malhas Digitais. 2015.

JORGE, V. C.; OESTREICH, E. F.; MAMEDE, J. S. S.; NASCIMENTO, D. A.; SOUZA, M. D.; SILVA, J. G. J.; DORVAL, A.. Diagnóstico fitossanitário da arborização urbana no bairro Cidade Alta, Cuiabá Mato Grosso, Brasil. Espacios, v.38, n.41, p.1-25, 2017.

KRAMER, J. A.; KRUPEK, R. A.. Caracterização florística da arvorização de praças públicas do município de Guarapuava, PR. Revista árvore, Viçosa, v.36, n.4, p.647-658, 2012. DOI: http://dx.doi.org/10.1590/S0100-67622012000400007

LIMA NETO, E. M.. Aplicação do Sistema de Informações Geográficas para o Inventário da Arborização de Ruas de Curitiba, PR. Dissertação (Mestrado em Engenharia Florestal) - Universidade Federal do Paraná, Curitiba, 2011.

LINDENMAIER, D. S.; SANTOS, N. O.. Arborização urbana das praças de cachoeira do Sul-RS-Brasil: fitogeografia, diversidade e índice de áreas verdes. Revista Pesquisas Botânicas, São Leopoldo, n.59, p.307-320, 2008.

MARCHETTI, L.; NANNI, C.; VAI, N.. Principali problemi fitosanitari del verde urbano e relativi indirizzi di difesa. Informatore Fitopatologico, 1997.

MILANO, M. S.. Avaliação Quali-Quantitativa e Manejo da Arborização Urbana: Exemplo Maringá-PR. Tese (Doutorado em Engenharia Florestal) - Universidade Federal do Paraná, Curitiba, 1988.

MILANO, M.; DALCIN, E.. Arborização de vias públicas. Rio de Janeiro: LIGHT, 2000.

MILLER, R. W.; HAUER, R. J.; WERNER, L. P.. Urban forestry: planning and managing urban greenspaces. Waveland Press, 2015.

MOSER, P.; SILVA, A. C.; HIGUCHI, P.; SCHMITZ. V.. Inventário da arborização e distribuição de praças-jardim em bairros centrais e periféricos de um município no sul do Brasil. Revista Espacios, v.38, n.38, p.1-21, 2017.

PORTO, L. P. M.; BRASIL, H. M. S.. Manual de Orientação Técnica da Arborização Urbana de Belém: guia para planejamento, implantação e manutenção da arborização em logradouros públicos. Belém: Universidade Federal Rural da Amazônia, 2013.

RAGAZZI, A.. Le specie quercine e l'ambiente urbano: consigli per un coretto impiego e analisi delle problematiche sanitarie. Informatore Fitopatologico, v.6, p.41-44, 1998.

RAVEN, P. H.; EICHHORN, S. E.; EVERT, R. F.. Biologia Vegetal. 8 ed. Rio de Janeiro: Guanabara Koogan, 2014.

REDIN, C. G.; VOGEL, C.; TROJAHN, C. D. P.; GRACIOLI, C. R.; LONGHI, S. J.. Análise da arborização urbana em cinco praças do município de Cachoeira do Sul, RS. Revista da Sociedade Brasileira de Arborização Urbana, v.5, n.3, p.149-164, 2010.

ROPPA, C.; FALKENBERG, J. R.; STANGERLIN, D. M.; BRUN, F. G. K.; BRUN, E. J.; LONGHI, S. J.. Diagnóstico da percepção dos moradores sobre a arborização urbana na Vila Estação Colônia, Bairro Camobi, Santa Maria/RS. Revista da Sociedade Brasileira de Arborização Urbana, v.2, n.2, p.1130, 2007.

SANTOS, A. C. B.; SILVA, M. A. P.; SOUZA, R. K. Levantamento florístico das espécies utilizadas na arborização de praças no 
município de Crato, CE. Caderno de Cultura e Ciência, v.10, n.1, 2011

SANTOS, L. R.; SANTOS, E. A.; PINHEIRO, R. M.; FERREIRA, E. J. L.. Diagnóstico da arborização do Parque Urbano Tucumã, em Rio Branco-Ac. Revista da Sociedade Brasileira de Arborização Urbana, Piracicaba, v.12, n.2, p.103-116, 2017. DOI: http://doi.org/10.5380/revsbau.v12i2.63529

SANTOS, N. R. Z.; TEIXEIRA, I. F.. Arborização de Vias Públicas: Ambiente X Vegetação. Santa Cruz do Sul: Instituto Souza Cruz, 2001.

SILVA, L. M. G.. Doses e métodos de aplicação do paclobutrazol em mangueiras cv. Tommy Atkins. Dissertação (Mestrado em Administração) - Universidade Federal da Bahia, Cruz das Almas, 2000.

SILVA, L. M.; HASSE, I.; MOCCELIN, R.; ZBORALSKI, A. R. Arborização de vias públicas e a utilização de espécies exóticas: o caso do Bairro Centro de Pato Branco/PR. Scientia Agraria, Curitiba, v.8, n.1, p.47-53, 2007. DOI: http://dx.doi.org/10.5380/rsa.v8i1.8341

SILVA, M. A. G.; GUIMARÃES, J. M. J.; SILVA, N. F. C.; SANTOS, F. C. V.; UCKER, F. E.. Caracterização pluviométrica de Santarém - PA, Brasil. Revista Eletrônica de Educação da Faculdade Araguaia, v.10, n.1, p.112-120, 2016.

VERAS, L. M. S. C.. Plano de Arborização de Cidades Metodologia. In: CONGRESSO NORDESTINO DE ECOLOGIA RECIFE. Anais. Recife: UFRPE, 1986. p.8-14.

WIELEWSKI, P.; AUER, C. G.. Patologias de árvores urbanas na cidade de Curitiba. In: INTERNATIONAL CONGRESS AND EXHIBITION ON FOREST, 5; CONGRESSO E EXPOSIÇÃO INTERNACIONAL SOBRE FLORESTAS, 5. Anais. Curitiba, 1999.

A CBPC - Companhia Brasileira de Produção Científica (CNPJ: 11.221.422/0001-03) detém os direitos materiais desta publicação. Os direitos referem-se à publicação do trabalho em qualquer parte do mundo, incluindo os direitos às renovações, expansões e disseminações da contribuição, bem como outros direitos subsidiários. Todos os trabalhos publicados eletronicamente poderão posteriormente ser publicados em coletâneas impressas sob coordenação da Sustenere Publishing, da Companhia Brasileira de Produção Científica e seus parceiros autorizados. Os (as) autores (as) preservam os direitos autorais, mas não têm permissão para a publicação da contribuição em outro meio, impresso ou digital, em português ou em tradução. 